\title{
Building Zone Regulation Compliance Using LIDAR Data: Real-Life Tests in İstanbul
}

\author{
İsmail Büyüksalih
}

Istanbul Metropolitan Municipality, The Bosphorus Construction Consultancy Inc. BEYOĞLU, ISTANBUL-TR

E-mail: ibuyuksalih@yahoo.com

Received 18 January 2016

Accepted 03 March 2016

\begin{abstract}
Airborne Laser scanning systems with light detection and ranging (LIDAR) technology is one of the fast and accurate 3D point data acquisition techniques. Generating accurate digital terrain and/or surface models (DTM/DSM) is the main application of collecting LIDAR range data. The LIDAR technique facilitates the rapid production of models which contain ground and above surface objects in 3D (Jaafar et al., 1999). Today automatic / semi-automatic generation of 3D digital building models and other city furniture from LIDAR data is a very active area of scientific research (Elaksher and Bethel, 2002) indicates that manual surface reconstruction is very costly and time consuming, and the development of automated algorithms is of great importance. Currently with this LIDAR data in place, it is possible to derive models and information (e.g. the heights of the buildings).This paper focuses on and explains our efforts on automatically checking Buildings' Zoning Regulation Compliance by integrating geometric information derived from 3D LIDAR data and semantic information acquired from 2D Implementation Development Maps.
\end{abstract}

Keywords: LIDAR, İstanbul, 3D Digital Building Model

\section{Introduction}

\section{Airborne Lidar and Building Footprints}

The location of building boundary is a crucial prerequisite for geographical condition monitoring, urban management, and building reconstruction (Zhao, et al., 2015). The need to extract good-quality building footprints has grown due to their widespread use in various domains of spatial planning. Since planning is not possible without data inventories, automatic techniques become important in order to save time and resources (Prerna and Singh, 2016).

Airborne Light Detection and Ranging (LIDAR) is known as an active remote sensing technology. It actively transmits pulses of light toward an object of interest, and receives the light that is scattered and reflected by the objects. An airborne LiDAR system is typically composed of three main components: a laser scanner unit, a Global Positioning System (GPS) receiver, and an Inertial Measurement
Unit (Liu, 2008) (Figure 1). Airborne LIDAR systems derive irregularly spaced threedimensional (3D) point measurements of objects including ground, buildings, trees and cars scanned by the laser beneath the aircraft.

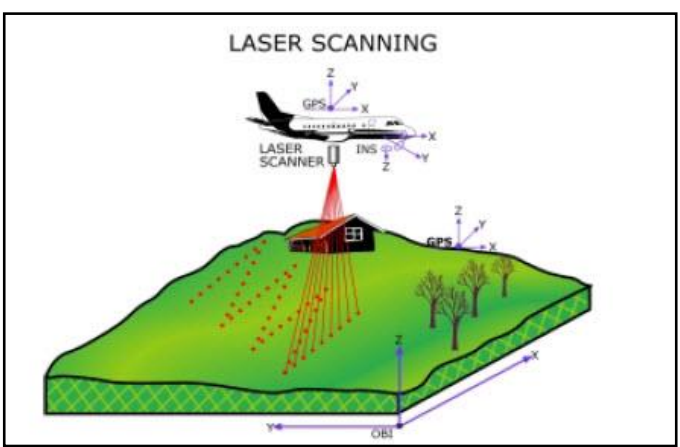

Figure 1. Airborne LIDAR System

As mentioned by Zhang et al.(2006) building footprints are one of the fundamental GIS data components that can be used to estimate energy demand, quality of life, urban population and property taxes in an urban environment. 
The current study compares three different approaches of building footprint extraction,

which are;

1. LiDAR point cloud-based classification,

2. OOC-based classification applied on aerial photographs,

3. LIDAR point cloud-derived DSM classification. Further, the authors have aimed to validate the methods by comparing the resultant footprints based on quantitative and qualitative statistical analysis discussed in the subsequent sections
Accurate building footprint data is considered as essential for construction of urban landscape models, assessment of urban heat island effect and estimation of building base elevation for flood insurance. Furthermore, footprint data in combination with height values can be used to generate 2,5D building models for visualization (Figure 3). As explained by Cheng et.al (2008) in order to obtain the segmented building points from raw LiDAR data, the first process is usually to separate the ground points from nonground points, and then identify the building points from non-ground points.

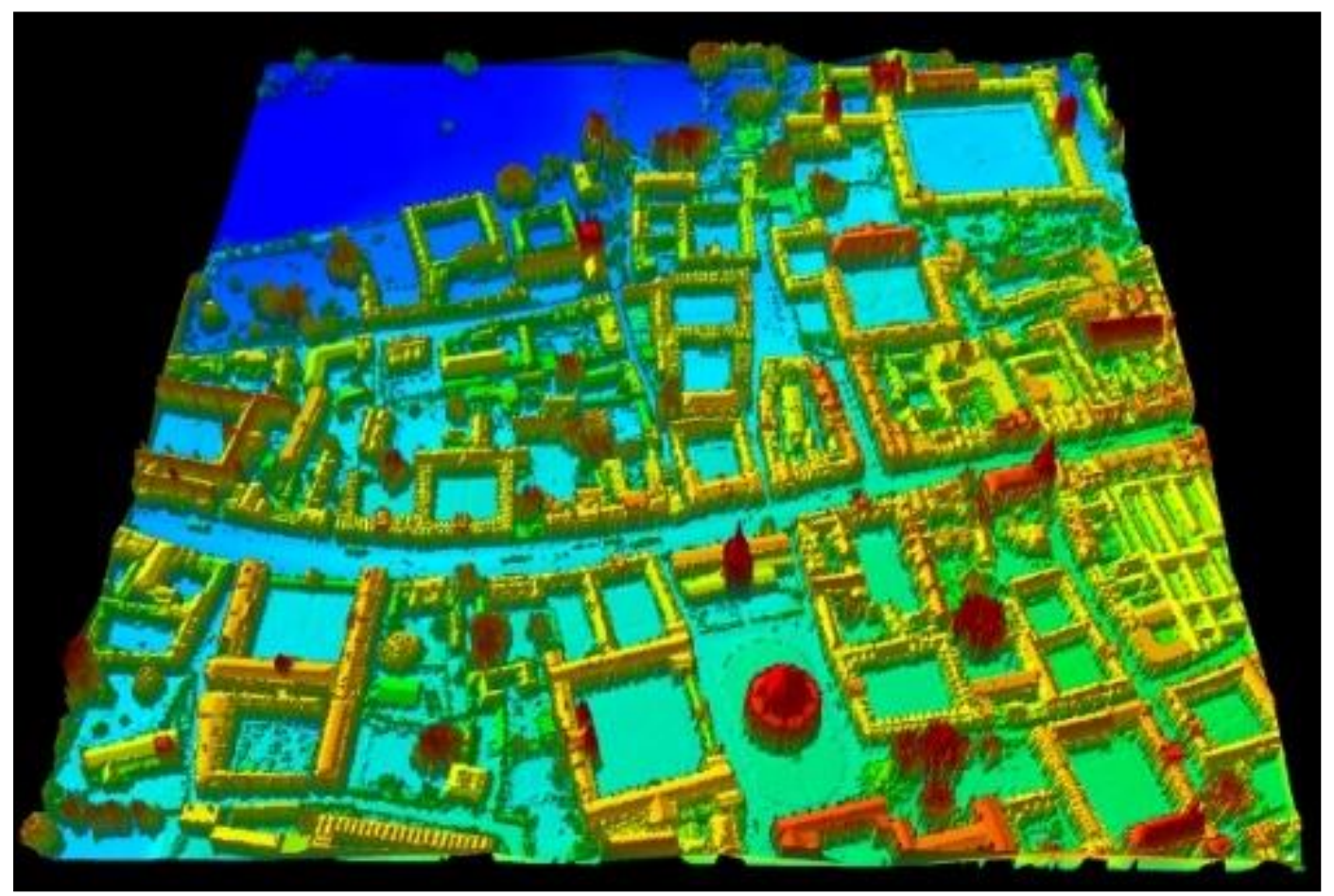

Figure 2. Building Footprints

As a main module of digital earth, 3D building models have a wide variety of applications in urban planning, virtual reality and change detection. Due to the fast acquisition speed and accurate 3D coordinates (horizontal and vertical), LIDAR point clouds have been one of the most important data source for high-quality 3D building model generations. 


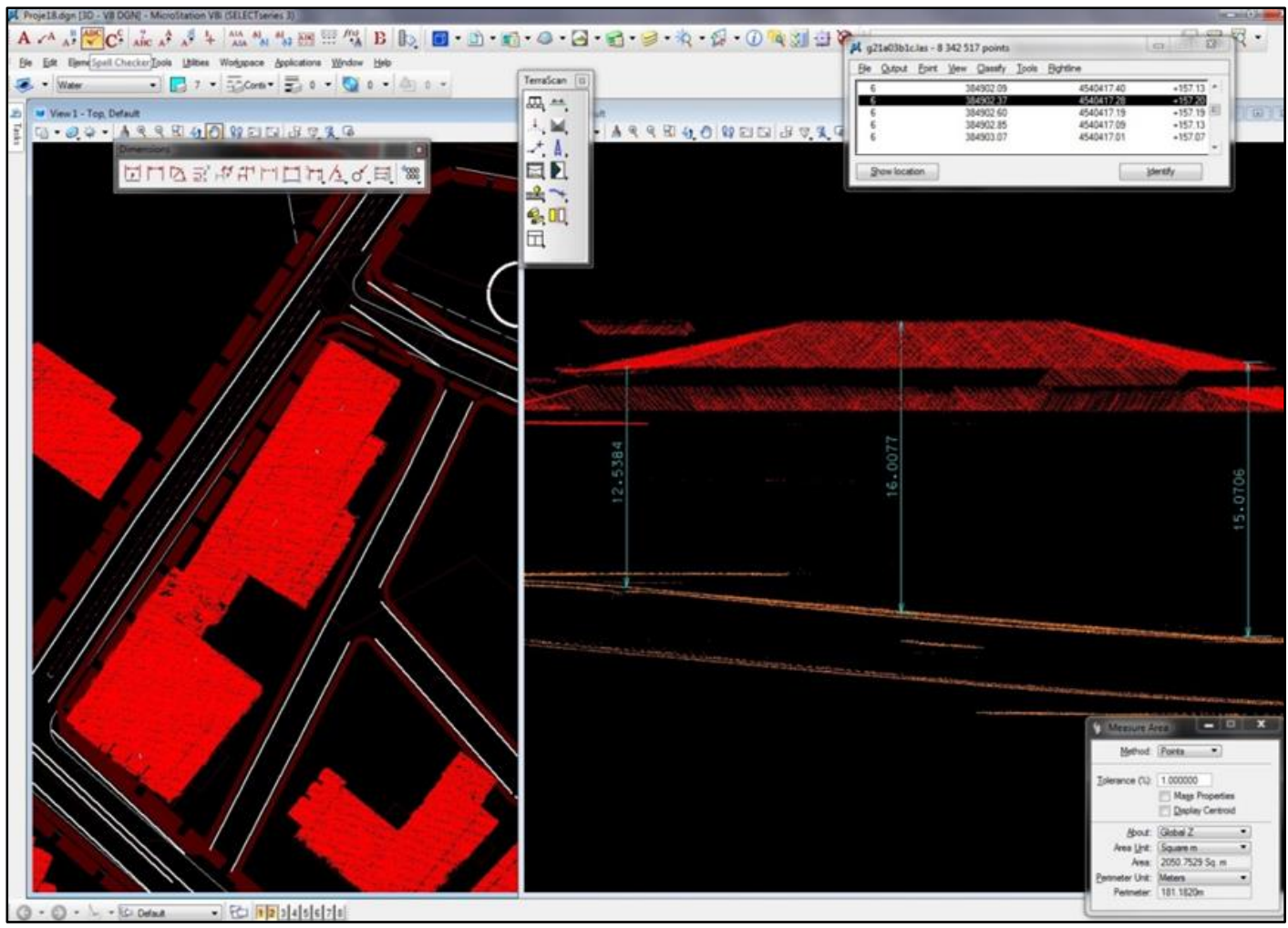

Figure 3. Building Heights

\section{Data Acquired from Implementation Development Plans}

Recent research illustrated that building density indicators such as Building Coverage Ratio (BCR), Floor Area Ratio (FAR), and other ones can be numerically and automatically derived from Building Representations in highresolution airborne LIDAR data. Bailang et al (2010) explained that the recognition of building objects in LIDAR data and their association with land lots and urban districts allow for the calculation of various building density attributes.
The building density attributes derived in their analysis include three types:

1. Geometric and volumetric attributes for individual buildings;

2. Density attributes at the land lot scale,

3. Geometric, volumetric and density attributes at the urban district scale.

These attributes are used to characterize and analyses the physical form and structure of the urban landscape for environmental studies and land use management at different scales.

In zoning studies, Building Coverage Ratio (BCR) and Floor Area Ratio (FAR) (Figure 4). 


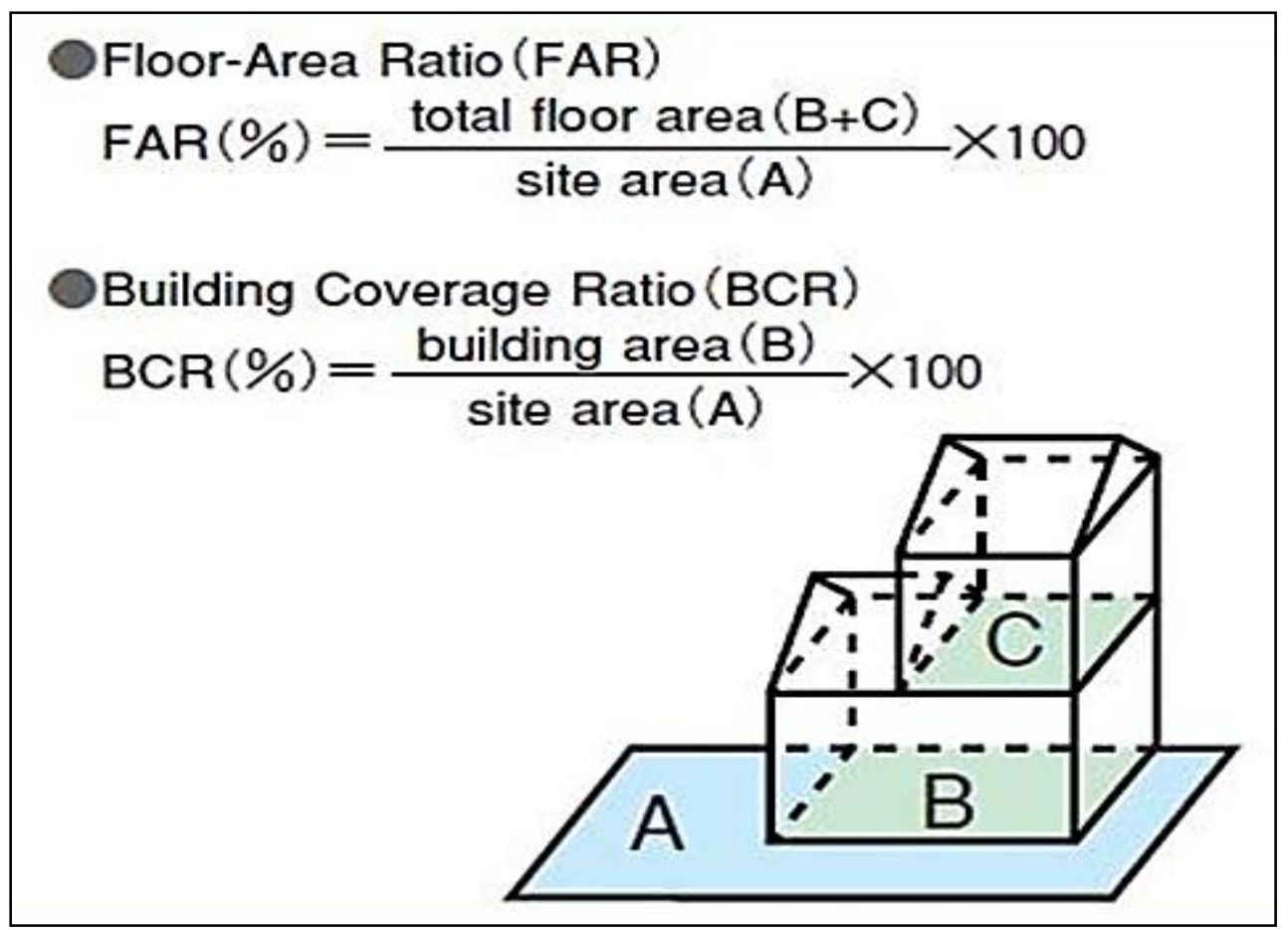

Figure 4. BCR and FAR

In Turkey zoning regulations that are enforced are indicated in "Implementation Development Plan"- a municipal plan controlling development and construction within an urban zone and includes all implementation details marked on a map scaled 1/1000 (Figure 5).

Additionally, the steps of determining building boundary from LIDAR data include the following:

1. Attribute filters for separating building candidate regions from lidar data,
2. Removing vegetation regions from building candidate regions by NDVI value of image,

3. Identifying and tracing building boundary,

4. Confirming the main directions of buildings and regularizing the building boundary line segments based on estimated main directions (Zhao, et al. 2015). 


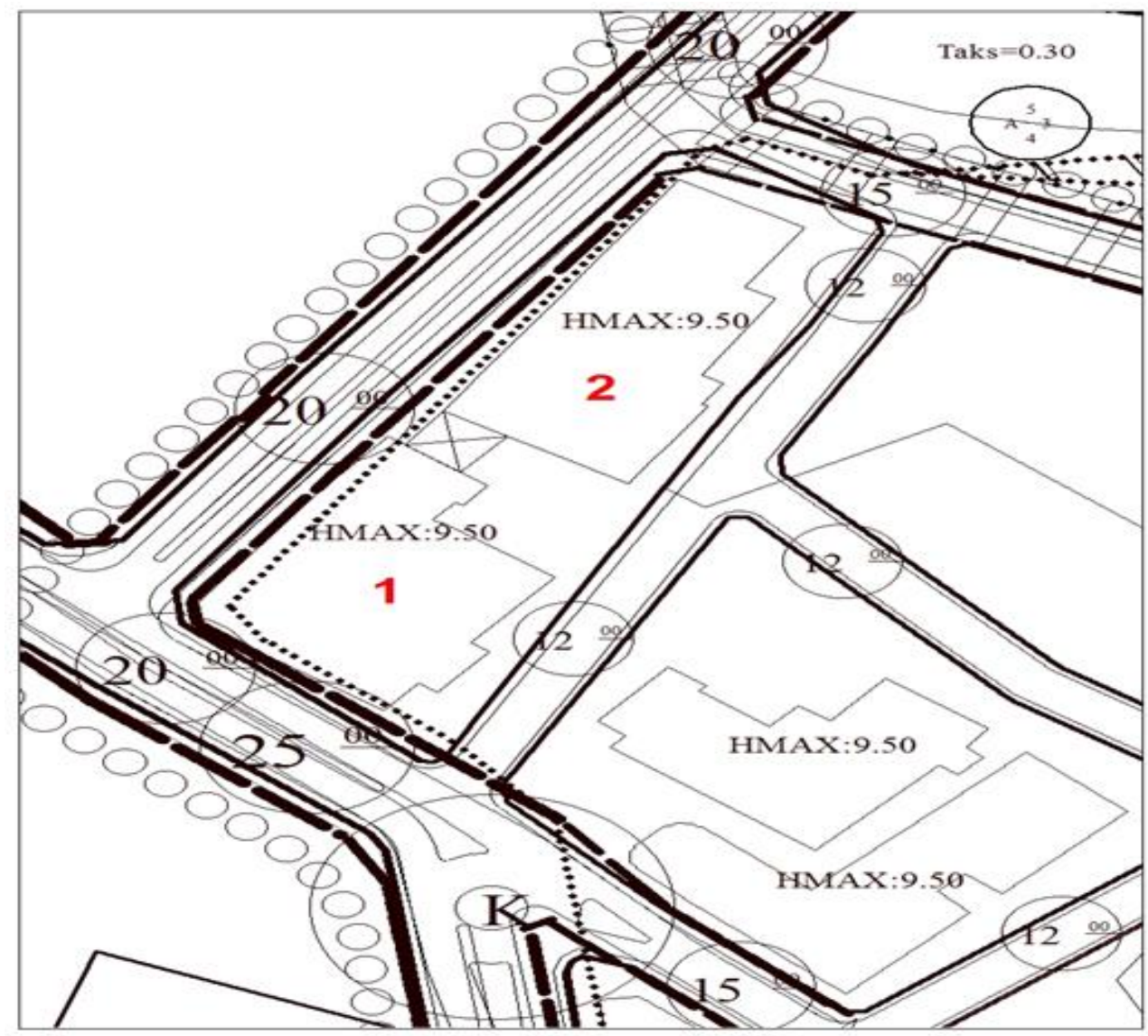

Figure 5. Sample of Implementation Development Plan

The Implementation Development Maps (scaled 1/1000) are prepared by municipalities, based on Implementation Development Plans of that city, and all implementation details of the zoning regulations are shown as marked in these 2D Maps. Similar to many countries, Turkish zoning regulations enforced in Implementation Development Plans focus on 3 metrics, Building Coverage Ratio (BCR) and Floor Area Ratio (FAR) and HMax. The BCR can be defined as the ratio of the building coverage area (i.e. the area of building footprint) to the size of land lot. Since the footprint represents the planimetric shape of a building, the BCR measures the building density in two-dimension (2D) space (Bailang et al., 2010) The Floor Area Ratio (FAR) can be defined as the ratio of gross building floor area to the size of land lot (Figure 6). The value of FAR is determined not only by the planimetric shape of the building, but also by the vertical distribution of the floors in different height, thus it depicts the three-dimensional (3D) building density. 


\section{FAR Illustrated}

Every zoning district has a floor area ratio (FAR).

Multiplying the FAR by the lot size will give you the permitted

floor area (size) of a building.

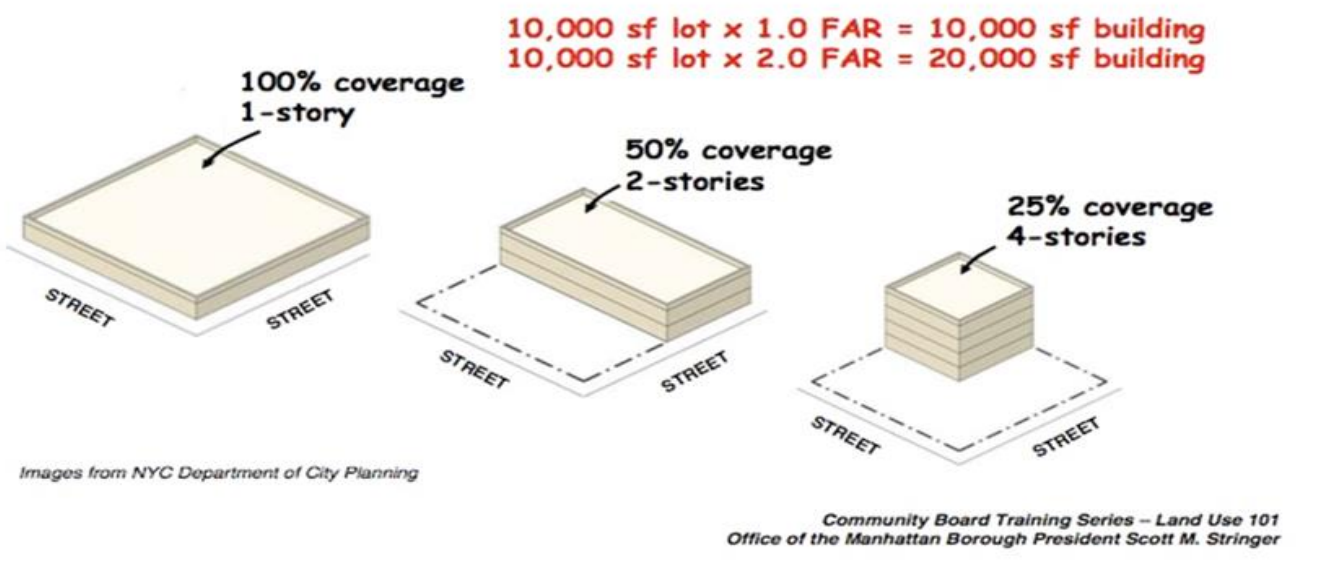

Figure 6. Floor Area Ratio (FAR)

\section{Automatic Check Processing}

To reduce the process error, it is necessary to increase the accuracy of matching the feature points at ground to the corresponding points at image /Yu, et al., 2005). The HMax can be defined as the maximum allowable height of the building. For instance, for a given land lot of 1000 sqm. if $\mathrm{BCR}=0.5$ and $\mathrm{FAR}=2$ and Hmax $=20$, the proposed building can have 4 floors with total gross area of 2000 sqm where the area of building footprint is $500 \mathrm{sqm}$, or can have 5 floors again with total gross area of 2000 sqm, but in this second case the area of building footprint needs to be $400 \mathrm{sqm}$. In fact, a building with a footprint area of $500 \mathrm{sqm}$ cannot have 5 floors (which would exceed FAR=2). In addition the height of the building cannot exceed the gived HMax for that lot. Considering $300 \mathrm{~cm}$ as the average floor height for a regular building in Turkey, HMax for the given case do not allow buildings with 7 floors (Figure 7-8). 


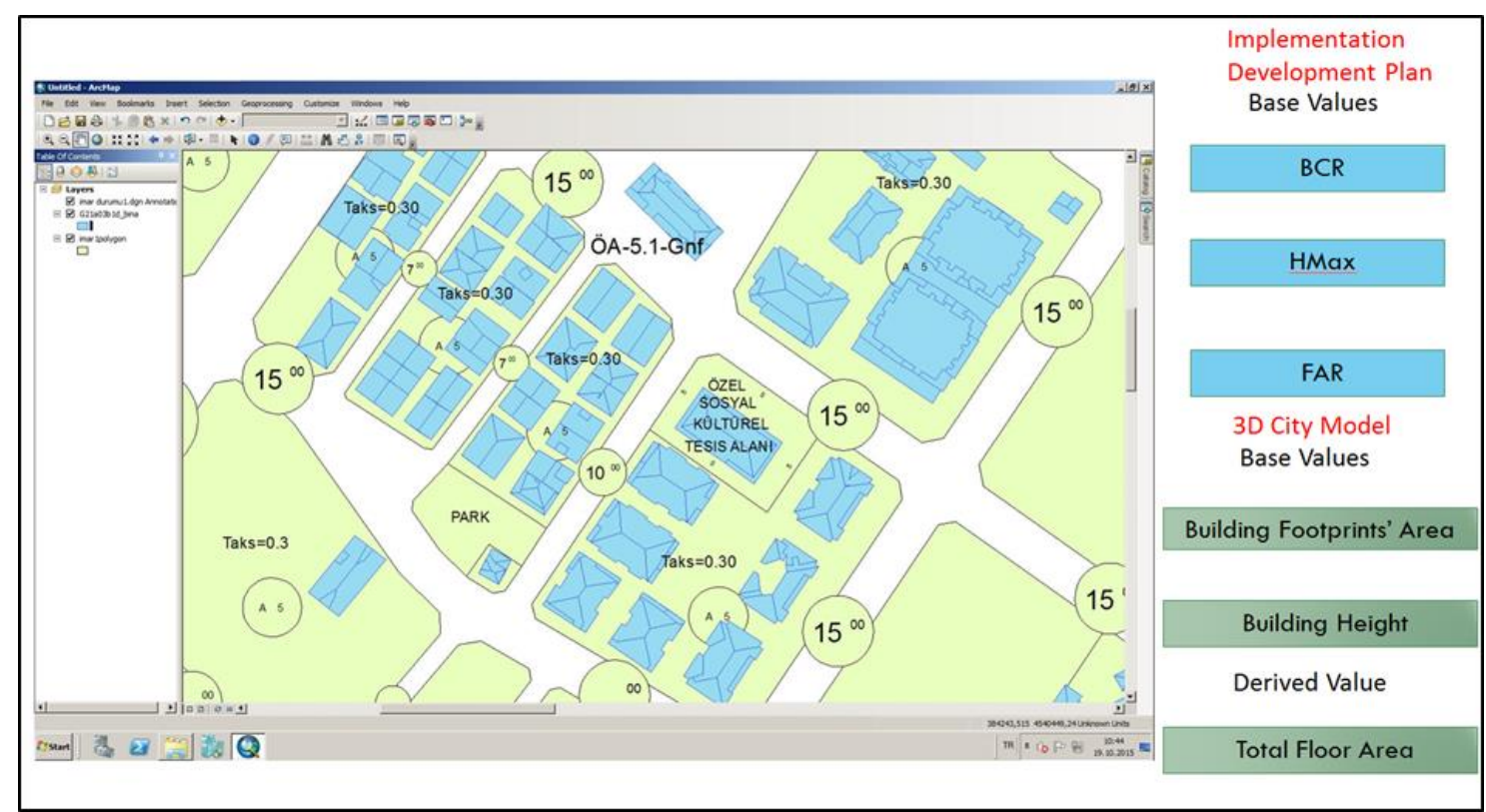

Figure 7. Combined model

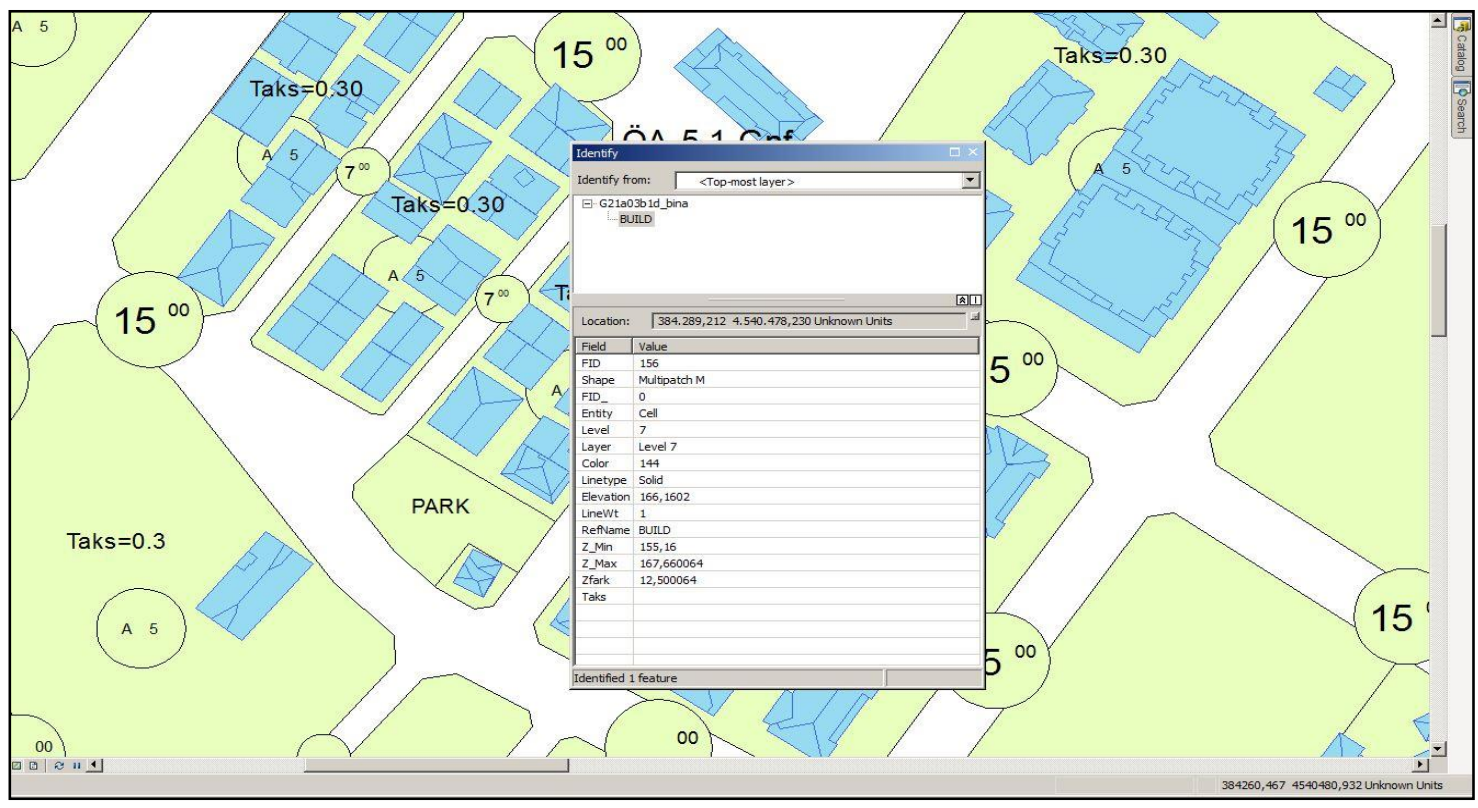

Figure 8 . Automatic zoning rule check by combined model in GIS environment 


\section{Conclusion}

Although the projects are checked prior to the start of the construction by municipalities, in metropolitan cities such as Istanbul, Ankara, Izmir, it observed in practice that final form of the constructed buildings do not conform / comply with the zoning regulations. Acquiring accurate footprints for complicated building structures occasionally pose an issue because each building may not be calmly covered by LIDAR signals and tall buildings may oversleuth the coverage of lower ones. Furthermore in mega-cities such as Istanbul, there have been a great number of buildings that had been built without taking permission from municipal authorities and these are termed as "Illegal Construction or Illegal Buildings". Since a long time, these buildings (i.e. the building that do not conform with zoning regulations) are considered as one of the biggest problems in urban development in Turkey. In Turkey all the building projects are checked prior to the start of the construction process if they conform the allowed BCR, FAR and HMax.

In this study, we reached automatic check prosess by using combined 3D city model and implementation development plan. Whether the building heights have been demonstrated according to plans. Our test results revealed that the approach holds a great potential for Buildings' Zoning Regulation Compliance. Automatic zoning rule check by combined model in GIS environment in Figure 8. It shows that implementation plan entegrated 3D city model represents the complience very well. Thus it is possible to check suitable plan for urban design concepts.

\section{References}

Bailang,Y. Hongxing,L Jianping,W. Yingjie,H. and Li, ,Z. 2010, Automated derivation of urban building density information using airborne LiDAR data and object-based method. Landscape and Urban Planning. 98(3-4), 210-219.

Cheng, L. Gong, J. Chen, X and Han, P. 2008. Building boundary extraction from high resolution imagery and LiDAR data. The International Archives of the Photogrammetry, Remote Sensing and Spatial Information Sciences. Vol. XXXVII. Part B3b.

Elasksher, A. and Bethel, J. 2002. Building Extraction Using Lidar Data, ASORSACSM Annual Conference and FIG XXII Congress, Apr. 22-26, 2002.

Jaafar, G. Priestnall, P. and P.M. Mather, 1999. The effects of LIDAR DSM grid resolution on categorising residential and industrial buildings. Proceedings of the ISPRS Workshop, 9-11 NOVEMBER 1999, La Jolla, USA.

Liu, X. 2008. Airborne LiDAR for DEM generation: some critical issues Progress in Physical Geography, Vol. 32, No. 1. pp. 3149.

Prerna, R. and Singh, C.K. 2016, Evaluation of LiDAR and image segmentation based classification techniques for automatic building footprint extraction for a segment of Atlantic County, New Jersey, Geocarto International, Volume 31(6), pp.694-713.

Yu, TT., Yang, M., Chen, CS, 2005, Automatic feature extraction and stereo image processing with genetic algorithms for LIDAR data, $2^{\text {nd }}$ International Conference on Computer Graphics, Imaging and Vision (CGVIS 2005), Beijing,, China, 26-29 July 2005.

Zhang, K. Yan, J.; Chen, S-C. 2006 Automatic Construction of Building Footprints From Airborne LIDAR Data, Geoscience and Remote Sensing, IEEE Transactions on , Vol.44, No.9, pp.2523,2533.

Zhao, Z., Duan, Y., Zhang, Y and Cao, R. 2015 Extracting buildings from and regularizing boundaries in airborne lidar data using connected operators, International Journal of Remote Sensing, Vol. 37(4), pp. 889912. 